\title{
Salivary Gland Adenocarcinoma Metastasis to the Brain in an Adult: A Case Report
}

\author{
Samadhan Pawar ${ }^{1}$, Chaitanya Borde ${ }^{1}$, Atul Patil ${ }^{1}$, Rajnish Nagarkar ${ }^{2}$ \\ ${ }^{1}$ Radiologist, Department of Radiology, HCG Manavata Cancer Centre, ${ }^{2} \mathrm{FRCS}$, Chief Surgical Oncologist and Managing Director, HCG Manavata Cancer Centre.
}

\section{Abstract}

Salivary gland malignancies are a heterogeneous group of 24 tumours that have unpredictable clinical behaviours and predilections for metastasis. Although salivary gland metastasis is an uncommon finding, it comprises of only 1-6\% of all malignancies in the head and neck region. It is a common clinical practice to surgically resect salivary gland tumours which is followed by radiation to the tumour bed. The overall combination of chemo-radiation approaches has helped clinically control the primary disease. However, many patients have presented with systemic metastasis including the brain. Long-term follow-up of such patients is an added value for radiologist and oncologists. We report an unusual case of salivary gland adenocarcinoma metastasis to the brain in an adult with a key focus on its radiological perspective.

Keywords: Salivary gland tumor; brain metastasis; radiology; adenocarcinoma.

Corresponding Author: Dr. Samadhan Pawar, Department of Radiology, HCG Manavata Cancer Centre, Off Nashik Freeway, Nashik422011.

Received: December 2018

Accepted: December 2018

\section{Introduction}

Salivary gland malignancies comprise of a heterogeneous group of tumours that have varying clinical behaviours and predilections for metastasis. As per current evidence, salivary gland cancers are relatively rare, comprising of 1$6 \%$ of all malignancies of the head and neck. ${ }^{[2]}$ The most common types of salivary gland carcinomas based on histopathologic types include mucoepidermoid carcinoma (MEC), adenoid cystic carcinoma (ACC), salivary duct carcinoma and adenocarcinoma. Many other malignant tumour variants such as a malignant mixed tumour, acinic cell carcinoma, clear cell carcinoma, and squamous cell carcinoma have been reported. ${ }^{[3]}$ In most cases, malignancies are reported in the parotid glands (70-80\%) followed by submandibular gland (10\%) and minor salivary glands $(5 \%) .{ }^{[3]}$ Correct diagnosis of salivary gland malignancies should be made based on clinical, radiographic, surgical, and microscopic findings.

We report an unusual case of salivary gland adenocarcinoma metastasis to the brain in an adult.

\section{Case Report}

A 48-year-old female presented with complaints of swelling in the right submandibular region in October 2017. The patient had undergone resection with neck dissection of the lesion.

\section{Investigation}

The preoperative positron emission tomography/computed tomography (PET-CT) showed an enlarged right submandibular gland. A heterogeneously enhancing lesion measuring $32 \times 31 \times 30 \mathrm{~mm}$ size abutting the right border of tongue posteriorly without any infiltration was observed [Figure 1]. An increased fluorodeoxyglucose (FDG) uptake was observed in the lesion (SUV max 5.3). Cortical erosion in the adjacent mandibular ramus was not observed. A biopsy of the lesion was performed which revealed adenocarcinoma of the salivary gland. The patient had received six cycles of paclitaxel and carboplatin regimen.

A complete response to therapy and resolution to a previously mentioned lesion in the right salivary gland was observed in the follow-up PET-CT. The right submandibular gland appeared atrophic/smaller in size than left with no obvious dominant lesion noted. No significant right cervical lymphadenopathy is noted. A small FDG avid node of $12 \times 9 \mathrm{~mm}$ in the in left level II with intact fatty hilum and 7x6 $\mathrm{mm}$ in left IB level which was reactive in nature was observed [Figure 2]. The patient continued with three more cycles of paclitaxel and carboplatin regimen along with 25 fractions of radiation. The patient was asymptomatic for three months.

\section{Follow-up}

The patient reported having a severe headache in October 2018. A follow-up CT scan was performed. A metastatic lesion measuring $4.1 \times 3.3 \times 3.8 \mathrm{~cm}$ with significant perilesional oedema with effacement of the left frontal horn was observed [Figure 3]. The magnetic resonance imaging (MRI) of the right salivary gland showed atrophied salivary 
gland without any recurrent mass lesion. The patient underwent a surgical excision of the tumour. The histopathology report confirmed it to be a metastatic adenocarcinoma. MRI imaging of right salivary gland region showing atrophied salivary gland without any recurrent mass lesion [Figure 4].

\section{Treatment}

The patient underwent whole brain radiation therapy (WBRT) along with an image-guided radiation therapy (IGRT) boost to the tumour bed. The patient received 30 Gray in 10 fractions. The patient and her family members were advised about her goals of care. She was transferred to regular hospice care. Salivary gland metastasis to the brain is an unusual clinical presentation.

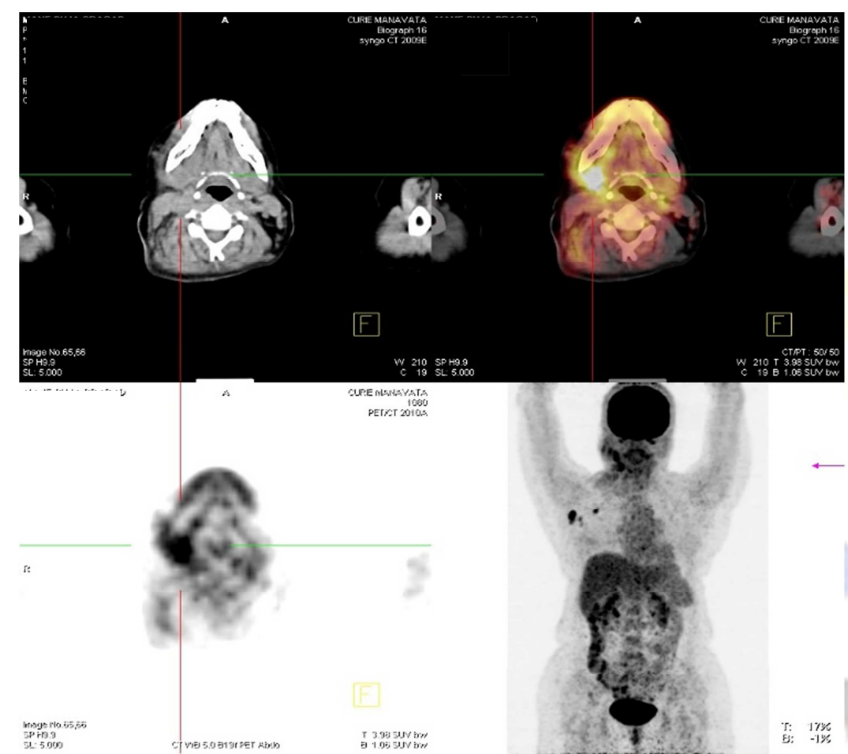

Figure 1: A heterogeneously enhancing lesion measuring $32 \times 31 \times 30 \mathrm{~mm}$ size abutting the right border of tongue posteriorly without any infiltration.



Figure 2: A small FDG avid node of $12 \times 9 \mathrm{~mm}$ in the in left level II with intact fatty hilum and $7 \times 6 \mathrm{~mm}$ in left IB level which was reactive in nature.

\section{Outcome and follow-up}

As per our knowledge and experience, salivary gland metastasis to the brain is an uncommon finding. We are based in a tier-2 city in India wherein salivary gland tumours are a common finding. However, brain metastasis is a rare occurrence. Although differential diagnosis based on radiographic and histopathological correlation, the follow-up radiological investigations helped in identifying the metastasized lesion. The patient is currently doing well and due for the next follow-up.

Informed Consent: A written informed consent was obtained from the patient for the purpose of publication.

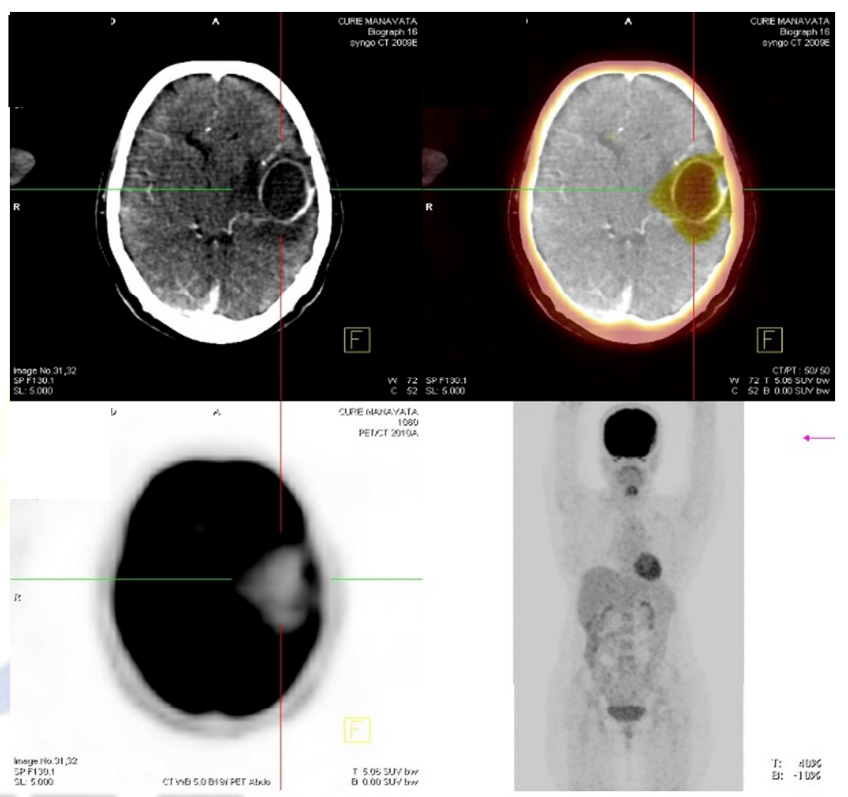

Figure 3. A metastatic lesion measuring $4.1 \times 3.3 \times 3.8 \mathrm{~cm}$ with significant perilesional oedema with effacement of the left frontal horn



Figure 4: MRI imaging of right salivary gland region showing atrophied salivary gland without any recurrent mass.

\section{Discussion}

Salivary gland tumours often represent a painless enlarging 
masses. These tumours are often uncommon and referred to the head and clinic. An estimated $20 \%$ of all salivary gland neoplasms are malignant while the remainder are benign. ${ }^{[4]}$ Low-grade basal cell adenocarcinoma of the parotid gland with metastasis to the brain has also been reported. ${ }^{[5]}$ In context to our case, wherein an MRI helped in confirming metastasis to the brain, the published case report had a similar radiological correlation. In a series of 44 operated patients, researchers have reported a single case of cerebellum metastasis to the brain from a primary salivary gland carcinoma. ${ }^{[6]}$ Salivary gland malignancies with intracranial extension have also been reported. ${ }^{[7]}$ These reports provide valuable information in context to distant metastasis of primary salivary gland tumours. The importance of regular follow-up of patients was reported in a recent report comprising of 51 patients with salivary gland malignancy. ${ }^{[8]}$ In context to the information shared by the researchers, we have reported a similar case on follow-up as well.

\section{Learning points}

- Salivary gland malignancies are known to have a prolonged course which may result in systemic metastasis.

- In most cases, the primary tumour is often treated surgically with post-operative radiation to the tumour bed.

- Salivary gland metastasis require the addition of chemothcrapy as obscrved in our casc.

- Although a combination of surgical and chemo-radiation therapies have increased the control of primary and systemic disease, the number of patients presenting with systemic brain metastasis has increased.

- Long-term follow-up of such patients can help identify distant metastasis efficiently.
- Our case report can help radiologists, oncologist, and radiotherapist assess and diagnose patients more effectively.

\section{Acknowledgment}

We would like to thank Mr. Lyndon Fernandes for his medical writing assistance.

\section{References}

1. Laurie SA, Licitra L. Systemic therapy in the palliative management of advanced salivary gland cancers. J Clin Oncol. 2006. ;24(17):2673-8.

2. Wang X, Luo Y, Li M, Yan H, Sun M, Fan T. Management of salivary gland carcinomas - a review. Oncotarget. 2016;8(3):39463956.

3. Venteicher AS, Walcott BP, Sheth SA, et al. Clinical features of brain metastasis from salivary gland tumors. J Clin Neurosci. 2013;20(11):1533-7.

4. To VS, Chan JY, Tsang RK, Wei WI. Review of salivary gland neoplasms. ISRN Otolaryngol. 2012;2012:872982.

5. Cui R, Cheng X, Li F, Zhuang H. Rare cerebral and pulmonary metastases from low-grade basal cell adenocarcinoma of the parotid gland. Clin Nucl Med. 2011 Dec;36(12):1124-6.

6. Pompili A, Carapella CM, Cattani F, Fabi A, Giannarelli D, Giovannetti $\mathrm{M}$, et al. Metastases to the cerebellum. Results and prognostic factors in a consecutive series of 44 operated patients. J Neurooncol. 2008;88:331-337.

7. Maiuri F, Gangemi M, Giamundo A, Mariniello G, Colella A, Vergara $\mathrm{P}$, et al. Intracranial extension of salivary gland tumors. Clin Neuropathol. 2010;29:9-13.

8. Van der Wal JE, Becking $\Lambda \mathrm{G}$, Snow GB, van der Waal I. Distant metastases of adenoid cystic carcinoma of the salivary glands and the value of diagnostic examinations during follow-up. Head Neck. 2002;24:779-783

Copyright: (C) the author(s), publisher. Asian Journal of Medical Radiological Research is an Official Publication of "Society for Health Care \& Research Development". It is an open-access article distributed under the terms of the Creative Commons Attribution Non-Commercial License, which permits unrestricted non-commercial use, distribution, and reproduction in any medium, provided the original work is properly cited.

How to cite this article: Pawar S, Borde C, Patil A, Nagarkar R. Salivary Gland Adenocarcinoma Metastasis to the Brain in an Adult: A Case Report. Asian J. Med. Radiol. Res. 2018;6(2):01-03.

DOI: dx.doi.org/10.21276/ajmrr.2018.6.2.1

Source of Support: Nil, Conflict of Interest: None declared 